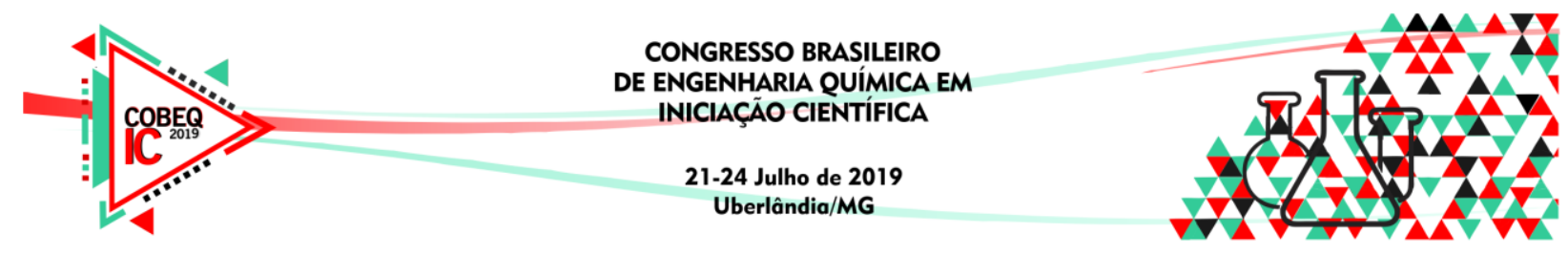

\title{
INFLUÊNCIA DO PROCESSO DE DESIDRATAÇÃO NAS PROPRIEDADES FÍSICAS DE OVO DE CODORNA EM PÓ
}

\author{
V. S. BERTOLANI ${ }^{1}$, L. R. ARAUJO ${ }^{1}$ e M. DE LIMA ${ }^{1}$ \\ ${ }^{1}$ Universidade Federal de Uberlândia, Faculdade de Engenharia Química \\ E-mail para contato: marieli@ufu.br
}

\begin{abstract}
RESUMO - O ovo de codorna é um produto apreciado no Brasil. No entanto, o produto in natura possui rápida deterioração e alto índice de perdas durante a cadeia produtiva. Nesse contexto, a desidratação é uma alternativa para estender a sua vida útil, facilitar o transporte e expandir seu mercado. O objetivo deste trabalho foi avaliar a influência do processo de secagem no $\mathrm{pH}$, cor instrumental e densidade aparente ( $\rho$ bulk) dos pós de ovo de codorna integral, do albúmen e da gema, obtidos por liofilização e por atomização em Spray-dryer. Quanto ao tipo de processo, a liofilização apresentou menor impacto sobre as condições físicas das amostras, principalmente na cor dos pós e no $\mathrm{pH}$ do albúmen e do ovo integral. $\mathrm{O} \mathrm{pH}$ e a densidade aparente foram influenciadas pelo processo de desidratação $(\mathrm{p}<0,05)$ no ovo integral e na gema, enquanto o albúmen não foi afetado. Para os dois processos de secagem, as amostras integrais apresentaram menor luminosidade $\left(\mathrm{L}^{*}\right)$ e valores positivos para $\mathrm{a}^{*}$, comportamento diferente do observado para os pós de gema e de albúmen. $\mathrm{O}$ parâmetro $\mathrm{b}^{*}$ apresentou, como esperado, valores mais altos para o os pós do ovo integral e da gema, indicando sua tendência à cor amarela. Em geral, os pós obtidos das amostras de ovo de codorna possuem características adequadas para um alimento desidratado.
\end{abstract}

\section{INTRODUÇÃO}

Os ovos de codorna têm sido bem requisitados no mercado. Segundo o IBGE (2016), sua produção girou em torno de 400 milhões de dúzias nos últimos anos. Estes dados demonstram que este é um produto com relevância comercial e apreciado por muitas pessoas. De acordo com Pastore (2012), o crescimento constante do consumo dos ovos de codorna dos últimos anos pode estar relacionado a fatores como mudanças sociais e hábitos alimentares, aumento da produção, que torna o produto mais acessível à população, melhor conhecimento da qualidade do produto, entre outros. Por ser um produto que possui certa fragilidade física e é susceptível ao desenvolvimento microbiológico, procuram-se alternativas para aumentar a vida útil do produto e diminuir perdas.

Os processos de desidratação de ovos permitem ao mesmo tempo aproveitar o enorme potencial nutricional e funcional do produto e seus componentes. Entre as vantagens, encontram-se a redução de problemas tais como: (a) dificuldade de conservação e degradação da qualidade interna; (b) fragilidade da casca ou perdas por quebras no transporte e armazenamento; (c) as diversas possibilidades de contaminação microbiana; e (d) o manuseio difícil com grandes quantidades de resíduos e cascas dentro da indústria alimentícia (Oliveira 


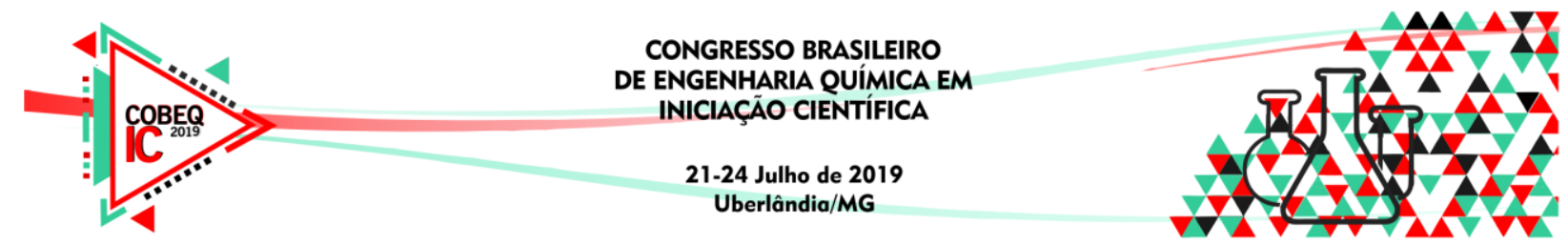

e Oliveira, 2013). Os processos de liofilização e de atomização podem suprir essa necessidade no ovo de codorna, além de inibir o crescimento microbiano e a atividade enzimática, diminui o volume de produto transportado, dispensa refrigeração e estende a vida útil do produto (Evangelista, 2005). Na atomização em Spray-dryer, as partículas pulverizadas do produto são submetidas à alta temperatura, reduzindo então a umidade, enquanto na liofilização, ocorre a redução de umidade a partir da sublimação, em condições de baixa pressão e temperatura (Fellows, 2006).

Os processos de desidratação podem resultar em um produto final com diferentes características quando comparados entre si, podendo a composição da amostra também influenciar nessas características (Fellows, 2006). A avaliação do pH, cor instrumental e densidade aparente podem contribuir na caracterização física do ovo desidratado. O estudo dos ovos de codorna e seu processamento industrial ainda é uma área pouco explorada, de forma que as informações sobre o desempenho do ovo integral, da gema e do albúmen do ovo de codorna nos processos de desidratação neste trabalho podem contribuir para se ter um maior aproveitamento do produto e uma gama maior de utilização comercial.

Frente ao exposto, o objetivo este trabalho foi estudar os efeitos dos processos de desidratação por atomização em Spray-dryer e liofilização sobre o pH, a cor instrumental e a densidade aparente dos pós obtidos do ovo de codorna integral, da gema e do albúmen.

\section{METODOLOGIA}

\subsection{Preparo da Matéria Prima e Desidratação do Ovo de Codorna}

Os ovos de codorna foram adquiridos no comércio local da cidade de Patos de Minas MG, e foram selecionados com base na data de obtenção e de validade. Após a ruptura da casca, foram separados três tipos de amostra: (a) ovo integral; (b) gema e (c) albúmen. A gema foi separada do albúmen, e todas as amostras foram filtradas e homogeneizadas para a pasteurização, em Banho Ultratermostático SL - 152/18 - Solab, a $60^{\circ} \mathrm{C} / 3,5$ minutos para a eliminação de microrganismos patogênicos. Em seguida, todos os tratamentos foram submetidos ao liofilizador e à atomização no Spray-dryer.

Para o processo de liofilização, as amostras foram congeladas no Ultra Freezer CL520 $86 \mathrm{~V}$ a $-74^{\circ} \mathrm{C}$ por um período de 12 horas, e então foram submetidas à liofilização em Liofilizador L101- Liotop ${ }^{\circledR}$ por 24 horas, a $500 \mu \mathrm{Hg}$ e $-50^{\circ} \mathrm{C}$. Após o processo, as amostras secas foram retiradas das bandejas e trituradas em moinho de facas para formarem um pó.

A atomização das amostras foi realizada em equipamento Spray Dryer LM MSD 1.0 (Labmaq do Brasil, Ribeirão Preto, SP), com vazão da bomba peristáltica de 1,0 $\mathrm{mL} / \mathrm{min}$ e vazão de ar na câmara de $40 \mathrm{~L} / \mathrm{min}$, de acordo com as recomendações do fabricante. A atomização foi conduzida em temperatura de $120^{\circ} \mathrm{C}$, diâmetro do bico atomizador de $1,2 \mathrm{~mm}$ e vazão do bico atomizador de $1,65 \mathrm{~mL} / \mathrm{min}$. 


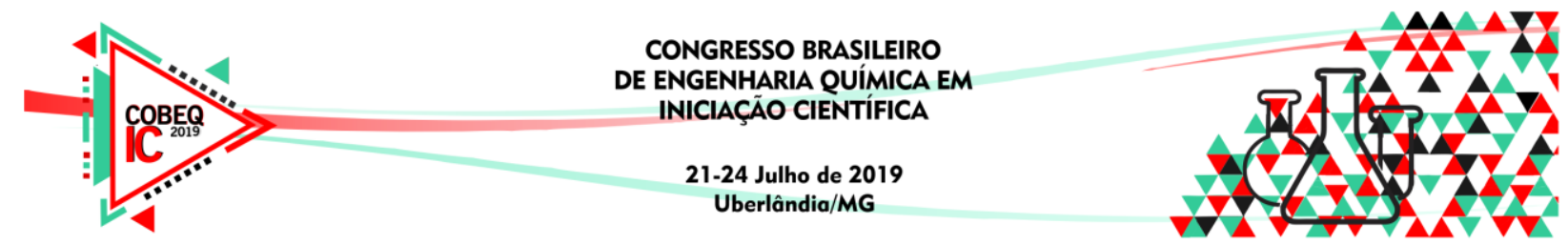

\subsection{Caracterização dos Pós de Ovo de Codorna}

Após os processos de desidratação, os pós obtidos foram submetidos às análises de $\mathrm{pH}$, de cor e de densidade aparente, como descrito abaixo:

pH: Determinada pela leitura direta das amostras em pHmetro, onde os pós foram solubilizados em água destilada na proporção de 1:10, de acordo com as Normas Analíticas do Instituto Adolfo Lutz (IAL, 2009).

Densidade bulk ( $\rho$ bulk) ou densidade aparente: As amostras foram medidas em uma proveta de volume conhecido, onde foi mensurada a massa e em seguida foram feitas as leituras do volume ocupado pela massa. Pela Equação 1, foi calculada a densidade aparente dos pós atomizados e liofilizados, expresso em $\mathrm{g} / \mathrm{cm}^{3}$.

$$
\text { pbulk }=\text { massa/volume ocupado pela massa }
$$

Colorimetria: A cor dos pós foi determinada em leitura direta das amostras em colorímetro Minolta modelo CR-400. Foram avaliados os parâmetros de cor das escalas CIELab, onde: L* (luminosidade, 0 a 100 - preto ao branco) e as coordenadas de cromaticidade $\mathrm{a}^{*} \mathrm{e}^{*}$ que indicam $(-\mathrm{a}=$ verde $\mathrm{e}+\mathrm{a}=$ vermelho; $-\mathrm{b}=$ azul $\mathrm{e}+\mathrm{b}=$ amarelo).

As triplicatas da caracterização dos pós foram submetidas à análise de ANOVA e a comparação de médias para os fatores processo de desidratação e tipo de amostra $(p<0,05)$ foi realizada através do teste de Tukey. Para tais análises, foi utilizado o software Statistica.

\section{RESULTADOS E DISCUSSÕES}

$\mathrm{O}$ pH das amostras de ovo em pó integral e do albúmen diferiram estatisticamente $(\mathrm{p}<0,05)$ quanto ao método de desidratação, enquanto a gema em pó não foi afetada pelos processos, conforme apresentado pela Tabela 1.

Tabela 1 - Média do pH dos pós de ovo de codorna desidratados.

\begin{tabular}{|c|c|c|}
\hline Tipo de Amostra & $\begin{array}{c}\mathrm{pH} \\
\text { Atomização }\end{array}$ & $\begin{array}{c}\mathrm{pH} \\
\text { Liofilização }\end{array}$ \\
\hline \hline Integral & $8,49^{\mathrm{aA}} \pm 0,04$ & $9,21^{\mathrm{bA}} \pm 0,02$ \\
\hline Gema & $6,32^{\mathrm{aB}} \pm 0,01$ & $6,40^{\mathrm{aB}} \pm 0,07$ \\
\hline Albúmen & $10,60^{\mathrm{aC}} \pm 0,02$ & $9,57^{\mathrm{bC}} \pm 0,02$ \\
\hline
\end{tabular}

Letras maiúsculas entre linhas: diferem quanto ao tipo de amostra.

$\mathrm{O}$ tratamento térmico, associado às diferentes estruturas dos componentes estudados, podem resultar em maior diferença no $\mathrm{pH}$ do albúmen em pó. Um estudo realizado por Oliveira e Oliveira (2013) mostra que após o armazenamento do ovo de codorna in natura, no período de 7 dias, o $\mathrm{pH}$ do albúmen foi de 9,16, valor próximo do obtido nesse estudo para os pós de albúmen reconstituídos, sendo possível também a influência da idade de postura do ovo ter influenciado nos valores de $\mathrm{pH}$ após a reidratação dos pós. 


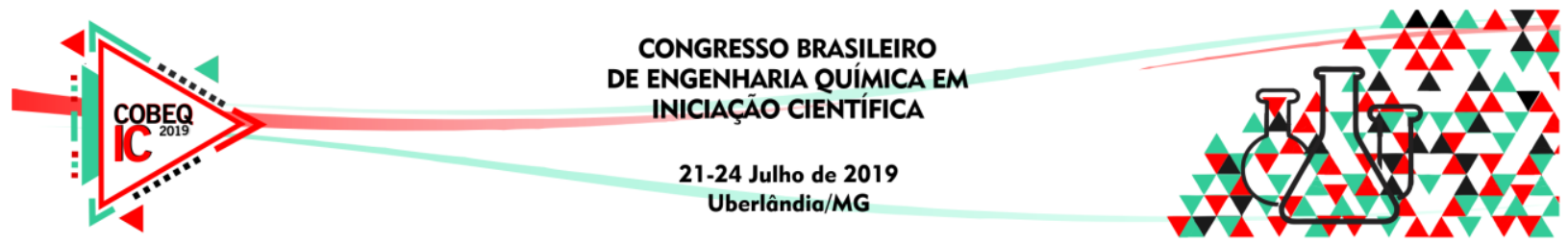

Conforme esperado, o $\mathrm{pH}$ apresentou diferença significativa $(\mathrm{p}<0,05)$ entre todas as amostras dos pós, independente do processo de desidratação ao qual foram submetidos. Isso se deve à composição dos diferentes elementos que integram o ovo. O albúmen de ovos é composto majoritariamente por água, seguido por proteínas e apenas traços de minerais e carboidratos, o que resulta em teor de $\mathrm{pH}$ variável entre 7,9 até acima de 9,5 (Santos et al., 2016). Esses mesmos autores ainda afirmam que o pH do albúmen de ovos de codorna apresentou maior pico de $\mathrm{pH}$ do que o ovo de galinha no armazenamento, o que pode justificar o valor mais elevado $(10,60)$ para o albúmen obtido neste trabalho. Por outro lado, a gema possui maior proporção de lipídios (34\%), seguida por proteínas e minerais e sua composição, resultando em pH entre 6,0 a 6,9, que corroboram com o obtido neste trabalho. A Legislação Brasileira não limita uma faixa de valor de $\mathrm{pH}$ para o ovo de codorna processado de tal maneira, considerando apenas valores para o produto em conserva.

As coordenadas de cromaticidade da cor instrumental $\left(\mathrm{L}^{*}, \mathrm{a}^{*}\right.$ e $\left.\mathrm{b}^{*}\right)$ dos pós encontramse na Tabela 2.

Tabela 2 - Média dos valores de $\mathrm{L}^{*}, \mathrm{a}^{*}$ e $\mathrm{b}^{*}$ obtidos das diferentes amostras desidratadas.

\begin{tabular}{|c|c|c|c|c|}
\hline $\begin{array}{c}\text { Coordenada de } \\
\text { cromaticidade }\end{array}$ & Processo & Integral & Gema & Albúmen \\
\hline \hline \multirow{2}{*}{$\mathrm{L}^{*}$} & Atomização & $37,57^{\mathrm{aA}} \pm 0,39$ & $49,33^{\mathrm{aB}} \pm 2,57$ & $52,66^{\mathrm{aB}} \pm 1,96$ \\
\cline { 2 - 5 } & Liofilização & $35,84^{\mathrm{bA}} \pm 0,54$ & $47,03^{\mathrm{bB}} \pm 2,60$ & $41,10^{\mathrm{bC}} \pm 1,10$ \\
\hline \multirow{2}{*}{$\mathrm{a}^{*}$} & Atomização & $1,52^{\mathrm{aA}} \pm 0,09$ & $-1,25^{\mathrm{aB}} \pm 0,04$ & $-1,48^{\mathrm{aB}} \pm 0,07$ \\
\cline { 2 - 5 } & Liofilização & $3,20^{\mathrm{bA}} \pm 0,02$ & $-2,30^{\mathrm{bB}} \pm 0,38$ & $-2,31^{\mathrm{bB}} \pm 0,19$ \\
\hline \multirow{2}{*}{$\mathrm{b}^{*}$} & Atomização & $12,59^{\mathrm{aA}} \pm 0,29$ & $13,43^{\mathrm{aA}} \pm 0,48$ & $5,13^{\mathrm{aB}} \pm 0,27$ \\
\cline { 2 - 5 } & Liofilização & $21,63^{\mathrm{bA}} \pm 0,14$ & $27,84^{\mathrm{bB}} \pm 1,95$ & $8,38^{\mathrm{bC}} \pm 0,35$ \\
\hline
\end{tabular}

Letras minúsculas entre linhas: diferem quanto ao processo; Letras maiúsculas entre colunas: diferem quanto ao tipo de amostra.

Os valores encontrados para $\mathrm{L}^{*}, \mathrm{a}^{*} \mathrm{e} \mathrm{b}^{*}$ se diferem estatisticamente $(\mathrm{p}<0,05)$ quanto ao processo de desidratação. O ovo integral in natura, quando misturado, apresenta coloração amarela predominante devido aos pigmentos naturais da gema, podendo as tonalidades de claro/escuro variar entre ovos oriundos de diferentes codornas.

Os valores de L* para as amostras atomizadas em Spray-dryer apresentaram um valor mais elevado para esse método de secagem. Oliveira e Oliveira (2013) ressaltam que a diminuição da cor dos ovos pode ocorrer devido à uma complexação do $\beta$ - caroteno com a $\beta$ - ciclodextrina durante o processo de redução do colesterol, o que pode causar uma tendência à uma coloração mais escura do pó. Wu et al. (2015) ainda ressaltam que as alterações de cor promovidas pelo processo de secagem são complexas e podem ser atribuídas às reações de oxidação ocorrentes no processo.

Os valores negativos de $\mathrm{a}^{*}$ para o albúmen indicam uma tendência ao aumento da cor verde, que foram mais evidentes na liofilização do que na atomização. $O$ mesmo comportamento foi encontrado na secagem de albúmen de ovo de galinha por $\mathrm{Wu}$ et al. (2015). Para os dois processos de secagem, os pós de gema obtiveram resultados próximos aos dos encontrados para o albúmen, enquanto que as amostras de pó integral apresentaram valores positivos para $\mathrm{a}^{*}$, indicando sua tendência ao aumento da cor vermelha. 


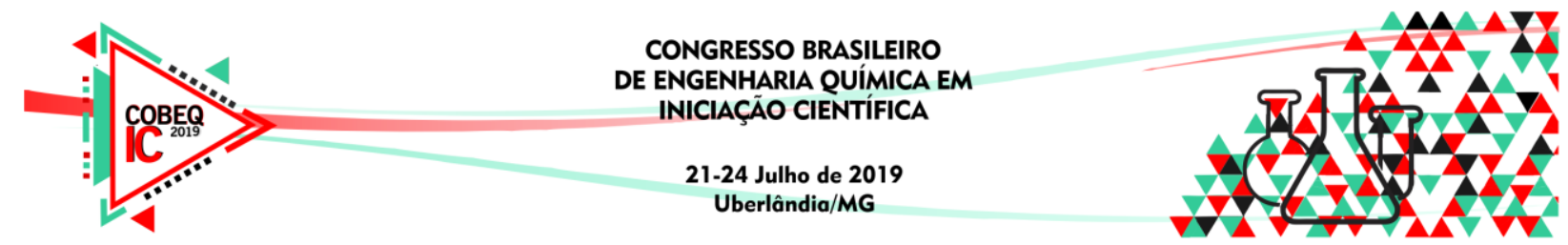

O parâmetro $b^{*}$ no ovo em pó liofilizado foi mais elevado, o que sugere que o método pode ser o mais indicado quando se deseja obter um pó com coloração mais amarelada. Os valores mais baixos de $b^{*}$ na gema e no ovo integral atomizados podem indicar uma possível degradação nos carotenoides presentes na gema (responsáveis pela coloração amarela), e pode ser atribuída ao tratamento térmico, característico deste método. Em contrapartida, os valores de $b^{*}$ foram maiores na liofilização, o que também foi encontrado por $\mathrm{Wu}$ et al. (2015) em ovos de galinha liofilizados.

A densidade aparente das amostras de pó integral e do albúmen diferiram estatisticamente quanto ao processo de desidratação, enquanto na gema em pó as médias são estatisticamente iguais para os dois processos. Rannou et al. (2015) relataram em seu trabalho que a densidade da gema de ovo de galinha em pó foi maior para a liofilização do que na atomização, constatando que tal resultado se deve à irregularidade das partículas (tamanho e forma) obtidas da liofilização, um comportamento que também se observa na densidade dos pós de albúmen obtidos neste trabalho. No entanto, o inverso ocorreu nas amostras de pó integral, o que pode evidenciar as diferentes granulometrias dos pós gerados por trituração pós processo de liofilização.

Tabela 3 - Média dos valores de $\rho$ bulk $\left(\mathrm{g} / \mathrm{cm}^{3}\right)$ obtidos das diferentes amostras desidratadas.

\begin{tabular}{c|c|c|}
\hline Tipo de Amostra & $\begin{array}{c}\text { Densidade bulk } \\
\text { Atomização }\end{array}$ & $\begin{array}{c}\text { Densidade bulk } \\
\text { Liofilização }\end{array}$ \\
\hline \hline Integral & $0,4000^{\mathrm{aA}} \pm 0,0500$ & $0,2800^{\mathrm{bA}} \pm 0,0040$ \\
\hline Gema & $0,2943^{\mathrm{aB}} \pm 0,0181$ & $0,2731^{\mathrm{aA}} \pm 0,0044$ \\
\hline Albúmen & $0,2855^{\mathrm{aB}} \pm 0,0133$ & $0,4748^{\mathrm{bB}} \pm 0,0341$ \\
\hline
\end{tabular}
Letras minúsculas entre colunas: diferem quanto ao processo;
Letras maiúsculas entre linhas: diferem quanto ao tipo de amostra.

Conforme esperado, a densidade variou $(\mathrm{p}<0,05)$ entre o tipo de amostra, o que pode estar relacionado às composições específicas de cada constituinte. Apenas a densidade da gema foi afetada pelo processo de secagem, possivelmente devido à sua maior proporção de sólidos (52\%), de lipídios (34\%) e de proteínas (17\%), tendo em vista que a gema é mais resistente às alterações pela temperatura do que o albúmen (Oliveira, 2013).

\section{CONCLUSÃO}

Os dois processos de desidratação podem ser indicados para a obtenção de ovo de codorna integral e de seus constituintes em pó, onde as amostras apresentaram propriedades físicas compatíveis aos ovos de galinha em pó comerciais. O processo de liofilização teve menor impacto sobre os parâmetros físicos, especialmente nos parâmetros de cor dos pós e no $\mathrm{pH}$ do albúmen e do ovo integral, onde a baixa temperatura da desidratação resultou em maior integridade das amostras.

\section{AGRADECIMENTOS}

À PROGRAD e ao CNPq pelo apoio financeiro na execução do projeto. 


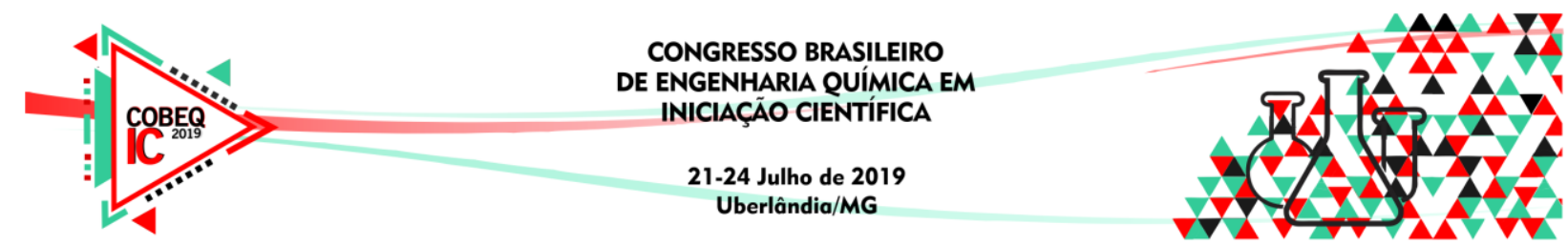

\section{REFERÊNCIAS}

EVANGELISTA, J. Tecnologia de alimentos. São Paulo: Atheneu, 284 652p., 2005.

FELLOWS, P. J. Tecnologia do Processamento de Alimentos: princípios e prática. Artmed, Porto Alegre, p. 602, 2006.

IBGE, Instituto Brasileiro de Geografia e Estatística, Produção da Pecuária Municipal 2015. http://biblioteca.ibge.gov.br/visualizacao/periodicos/84/ppm_2015_v43_br.pdf.

INSTITUTO ADOLFO LUTZ. Normas Analíticas do Instituto Adolfo Lutz. v. 1: Métodos químicos e físicos para análise de alimentos, São Paulo: IMESP, 1985. p. 25-26.

OLIVEIRA, B. L.; OLIVEIRA, D. D. Qualidade e Tecnologia de Ovos. Lavras: UFLA. p. 27 $-33,2013$.

PASTORE, S. M.; OLIVEIRA, W. P.; MUNIZ, J. C. Panorama da Coturnicultura no Brasil. Revista eletrônica Nutritine, v. 9, p. 2041 - 2049, 2012.

RANNOU, C., QUEVEAU D., BEAUMAL V., DAVID-BRIAND E, BORGNE C., MEYNIER, C., ANTON M., PROST C., SCHUCK P., LOISEL, C. Effect of spraydrying and storage conditions on the physical and functional properties of standard and enriched egg yolk powders. Journal of Food Engineering, 154, 58-68, 2015.

SANTOS, J.S.; MACIEL, L.G.; SEIXA, V. N. C.; ARAÚJO, J. A. Parâmetros avaliativos da qualidade física de ovos de codornas (Coturnix coturnix japônica) em função das características de armazenamento. Revista Desafios, v.3, n.1, 2016.

WU, Z.; YUE, L.; ZHANYONG, L.; LI, J.; MUJUMDAR, A. S.; REHKOPF, J. A. Pulse Combustion Spray Drying of Egg White: Energy Efficiency and Product Quality. Food Bioprocess Technology, v.8, p.148-157, 2015. 